\title{
A medicalização do sofrimento psíquico: considerações sobre o discurso psiquiátrico e seus efeitos na Educação
}

\author{
Renata Guarido \\ Universidade de São Paulo
}

\section{Resumo}

Este estudo analisa criticamente as mudanças observadas no tratamento do sofrimento psíquico na história recente, apontando a contribuição de fatores como: a padronização de sintomas trazida pelas sucessivas edições da série DSM (Manual Diagnóstico e Estatístico de Transtornos Mentais), os resultados de pesquisas na neurociência - que tentam fundamentar o funcionamento psíquico em bases orgânicas - e o grande desenvolvimento dos psicofármacos, fruto de maciços investimentos financeiros. A ação desse conjunto de fatores teve por efeito a perda da noção de sentido/ significado dos sintomas e dos sofrimentos subjetivos, própria da psiquiatria clássica, e a crescente medicalização dos indivíduos na sociedade contemporânea.

0 texto busca alinhavar como aconteceu a produção de uma nova verdade acerca dos sofrimentos psíquicos e amplia essa análise, evidenciando que os procedimentos de medicalização surgidos no cuidado da população adulta foram estendidos também para as crianças. Revê a evolução do tratamento da criança, marcando a interação da pedagogia e da medicina na constituição da psiquiatria infantil. Além disso, busca evidenciar os efeitos dessa verdade sobre os sujeitos, identificando a forma como o discurso técnico (especialmente influenciado pelo discurso médico-psicológico) tem tido lugar no mundo contemporâneo e como este tem influenciado a Educação. Trata de ressaltar, como produtos, a banalização da existência, a naturalização do sofrimento e a culpabilização dos indivíduos pelas vicissitudes da vida. Argumenta que a psicologização da escola pode ceder lugar hoje à psiquiatrização do discurso escolar. A articulação saber/verdade/ poder é aqui tratada a partir dos textos de Michel Foucault.

\section{Palavras-chave}

Medicalização - Criança - Subjetividade - Educação.

\author{
Correspondência: \\ Renata Guarido \\ Av. Cerro Corá, 85 casa 24 \\ 05061-050 - São Paulo - SP \\ e-mail: reguarido@ig.com.br
}




\section{The medicalization of the psychic suffering: considerations about the psychiatric discourse and its effects on Education}

Renata Guarido

Universidade de São Paulo

\begin{abstract}
This study offers a critical analysis of the changes observed in the treatment of psychiatric suffering in recent history, noting the contribution from factors such as: the standardization of symptoms brought by the successive editions of the DSM series (Diagnostic and Statistical Manual of Mental Disorders), the results of researches in neuroscience that attempt to establish the psychic functioning upon organic bases, and the huge development of psychopharmaceuticals as a result of massive financial investments. The combined action of this group of factors had as its effect the loss of the notion of sense/ meaning of the symptoms and subjective sufferings, which belongs to classical psychiatry, and the growing medicalization of the individuals in contemporary society.

The text seeks to outline a picture of how a new truth about the psychic sufferings was produced, and expands this analysis by showing that the medicalization procedures developed for the treatment of the adult population were extended also to children. It reviews the evolution of the treatment of children, marking the interaction between pedagogy and medicine in the constitution of child psychiatry. In addition to that, the text tries to reveal the effects of this truth upon the subjects, identifying the way in which the technical discourse (particularly influenced by the medicalpsychological discourse) has been given a place in the contemporary world, and how its has influenced education. It underlines, as products of this process, the banalization of existence, the naturalization of suffering, and the blaming of individuals for the accidents of life, and argues that the psychologization of school may nowadays be replaced by the psychiatrization of school discourse. The articulation knowledge/truth/power is investigated here from the texts of Michel Foucault.
\end{abstract}

\section{Keywords}

Medicalization - Child - Subjectivity - Education. 
Muitos têm sido os trabalhos que, percorrendo a história da psiquiatria, dedicam-se a analisar as mudanças históricas verificadas nos tratamentos propostos aos sofrimentos psíquicos. Entre as mudanças mais marcadamente assinaladas por tais trabalhos, verificadas ao longo dos últimos 50 anos, estão os novos procedimentos diagnósticos propostos a partir da produção da série DSM (Manual Diagnóstico e Estatístico de Transtornos Mentais), bem como os avanços da medicalização como forma majoritária de intervenção terapêutica na atualidade.

$\mathrm{Na}$ sua grande maioria, as análises focam a presença atual de diagnósticos psiquiátricos que estabelecem bases biológicas para os sofrimentos psíquicos, aproximando os fenômenos mentais das doenças orgânicas, ou seja, vê-se um abandono crescente da descrição causal e de sentido dos sintomas apresentados pelo sujeito em benefício de uma noção em que os sintomas são reconhecidos como manifestações de desordens da bioquímica cerebral (Aguiar, 2004; Silva Jr., 2004; Roudinesco, 2000; Birman, 1999).

A biologia é fundamento incontestável da psicopatologia na atualidade. As neurociências fornecem os instrumentos teóricos que orientam a construção da explicação psiquiátrica. Por esse viés, a psicopatologia pretende ter encontrado finalmente sua cientificidade, de fato e de direito. Além disso, a nova psicopatologia acredita ter encontrado enfim com sua vocação médica, em um processo iniciado no início do século XIX, na medida em que se fundaria no discurso biológico. (Birman, 1999, p. 180)

Data de 1952 a primeira sintetização de um psicofármaco utilizado em tratamentos psiquiátricos. Desde então, a indústria farmacêutica investe, ano após ano, mais e mais recursos no estabelecimento de pesquisas na área da psicofarmacologia e investe grande parcela de recursos no marketing de novas drogas.

Se o uso dos psicofármacos pôde ter alguns efeitos positivos associado às mudanças propostas no tratamento da loucura - empreendimentos pós-asilares e a constituição do campo de reflexão e intervenções em Saúde Mental na oferta de alternativas de acolhimento e tratamento da loucura (efeito dos trabalhos da antipsiquiatria e do Movimento de Luta Antimanicomial) -, atualmente a psicofarmacologia e a neuropsiquiatria ganham espaço hegemônico no tratamento de sofrimentos severos bem como de uma gama muito maior de sofrimentos cotidianos ${ }^{1}$.

Data também de 1952 a primeira versão da série DSM (Manual Diagnóstico e Estatístico de Transtornos Mentais) produzida nos EUA. Até 1980, quando se publica a versão DSM-111, os fundamentos do diagnóstico propostos por esses manuais expressavam influências da psicanálise e da psiquiatria social comunitária, ainda que pouco a pouco ganhasse ênfase a objetivação dos critérios diagnósticos baseados em experimentações científicas que afastavam cada vez mais a dimensão de sentido antes presente na consideração dos quadros psicopatológicos (Aguiar, 2004). Ainda segundo esse autor, cumpriram importante papel nas modificações teóricas do manual as questões econômicas envolvidas no incentivo de pesquisas americanas na área da psiquiatria. A falta de objetividade nos procedimentos psiquiátricos, antes da mudança estabelecida pelo DSM-111, bem como a falta de dados epidemiológicos acarretavam custos inadmissíveis pelas companhias seguradoras de saúde bem como pelos órgãos governamentais de incentivo à pesquisa em saúde mental.

O DSM-111 promoveu uma reviravolta no campo psiquiátrico, que se apresentou como uma salvação da profissão. Não se tratava apenas de disputas teóricas internas ou de progresso científico. Ele surge como efeito da presença cada vez maior de grandes corporações privadas no campo da psi-

1. A saber, por exemplo, a 'epidemia da depressão' presente nas sociedades ocidentais contemporâneas; sobre isso, ver o fundamental trabalho de Élizabeth Roudinesco (2000), bem como recente publicação de Maria Silvia Bolguese (2004). 
quiatria, como a indústria farmacêutica e as grandes seguradoras de saúde. 0 Congresso americano, que desacreditava o National Institute of Mental Health (NIMH) no começo dos anos 1970, justamente devido à baixa confiabilidade dos diagnósticos psiquiátricos, passou a aumentar os recursos financeiros destinados à pesquisa após o DSM-111. Em 1994, os fundos de pesquisa do NIMH chegaram a US\$ 600 milhões, bem mais que os US\$ 90 milhões de 1976, e, sob a influência do instituto, o congresso foi persuadido a declarar os anos 1990 como 'a década do cérebro'. (Aguiar, 2004, p. 42)

A versão DSM-111 rompe definitivamente com a psiquiatria clássica. A partir desta, os quadros psicopatológicos serão apresentados como transtornos mentais que serão diagnosticados a partir da presença de certo número de sintomas (identificados a partir de uma lista presente no manual para cada transtorno) e que devem estar presentes na vida do sujeito por um intervalo definido de tempo. Além disso, a psiquiatria americana consolida-se como discurso hegemônico e o DSM-IV revisado (última versão do manual) é atualmente referência mundial de diagnóstico dos transtornos mentais, globalizando o modelo psiquiátrico americano.

Considerando que a medicação é atualmente indicação prioritária das intervenções médico-psiquiátricas, associada a procedimentos diagnósticos descritivos, objetivados pelo discurso científico, bem como levando em consideração a socialização do discurso médico estabelecida pela mídia e as campanhas de marketing financiadas pela indústria farmacêutica, pode-se reconhecer em relevo o paradigma do discurso médico na produção de verdade acerca do sofrimento psíquico e de sua natureza. Se a psiquiatria clássica, de forma geral, esteve às voltas com fenômenos psíquicos não codificáveis em termos do funcionamento orgânico, guardando espaço à dimensão enigmática da subjetividade, a psiquiatria contemporânea promove uma naturalização do fenômeno humano e uma subordi- nação do sujeito à bioquímica cerebral, somente regulável pelo uso dos remédios.

Há aí uma inversão não pouco assustadora, pois na lógica atual de construção diagnóstica, o remédio participa da nomeação do transtorno. Visto que não há mais uma etiologia e uma historicidade a serem consideradas, pois a verdade do sintoma/transtorno está no funcionamento bioquímico, e os efeitos da medicação dão validade a um ou outro diagnóstico. 0 caráter experimental da administração de medicamentos pode ser acompanhado nos procedimentos médicos atuais, bem como a mudança dos diagnósticos pela variação dos sintomas apresentados em certo espaço determinado de tempo.

\section{A medicalização da criança e seus efeitos sobre a Educação}

Se nos textos encontramos análises da clínica psiquiátrica atual com adultos, sabemos por pesquisas recentes da crescente medicalização das crianças e da mesma lógica diagnóstica do DSM aplicada a seus sofrimentos psíquicos. No entanto, poucas são as análises que centram foco nesse fenômeno: a crescente medicalização da criança e a utilização dos paradigmas da clínica com adultos para a clínica psiquiátrica com crianças.

Bercherie, ao caracterizar a formação do campo da psiquiatria infantil, divide sua história em três grandes períodos, marcados por influências diversas e por formas distintas de apreensão dos fenômenos da infância. De forma resumida, apresenta: 1- a influência da pedagogia dos séculos XVIII e XIX; 2- os progressos da psicologia do desenvolvimento; e 3- as contribuições psicanalíticas nas definições da clínica psiquiátrica da criança.

0 que determina as questões, procedimentos e observações dos clínicos, é o olhar que eles lançam sobre a infância, a concepção que têm de seu desenvolvimento e de seu papel na formação do adulto. Durante os dois primeiros períodos [séc. XIX até primeiro terço do séc. XX], a criança é es- 
sencialmente concebida como um adulto 'em potência', no sentido aristotélico: o adulto não é somente o fim de seu desenvolvimento, mas também seu único conteúdo e seu sentido último. A psicologia da criança só começa realmente a existir como campo autônomo no final do séc. XIX [...]. Antes dessa época, é nas doutrinas pedagógicas que é preciso procurar as concepções clássicas sobre a infância. (Bercherie apud Cirino, 2001, p.139) ${ }^{2}$

Se até o início do século $X X$ a criança é basicamente objeto da pedagogia, é nesta que os primeiros médicos dedicados a enfrentar os problemas graves do desenvolvimento infantil vão encontrar parceria fértil para propor formas de tratamento a essas crianças. Pode-se dizer que o campo de tratamento da criança se instala imbricado a certo ideal de educação do início do séc. XIX.

0 ideal educativo, no início do século $\mathrm{XIX}$, já estava instalado na forma como hoje o conhecemos. Vinha, desde o século XV11, atribuindo contorno, a existência e o sentido que o discurso social designa para a criança, como nos mostra Philippe Ariès. Ariès demonstra que o novo sentimento de infância gestado a partir do século XVIl é totalmente solidário com um novo ideal educativo, construido de modo a atender às exigências político-sociais de uma burguesia nascente. 0 discurso social moderno cria uma criança cuja consistência está no fato de ela ser submetida a uma educação nova, que implica vigilância, disciplina, segregação. Que implica o surgimento da escola. Nossa criança é, por definição, escolar. (Kupfer, 2001, p. 42)

Interessava aos médicos de então tratar o que se configurava como desordens das condições das crianças em se tornarem adultos plenos no exercício de suas funções intelectuais e morais. Não é por acaso, então, que os historiadores da psiquiatria afirmam que nesse período a patologia fundamental recortada no campo médico para a criança fosse a idiotia retardo mental -, sendo que esta não tinha estatuto de doença mental.

As formas de tratamento presentes nesse período são descritas como médico-pedagógicas e se realizavam em serviços anexos aos asilos para loucos adultos. Ali estavam, segundo os autores, enormes contingentes de crianças idiotas.

0 trabalho desenvolvido por ltard com Victor de Aveyron é tomado como marco dessas abordagens de tratamento.

La importancia de la historia de Victor se mide por el doble deslizamiento de la práctica y de la reflexion científicas de las que es la ocasión y el punto de apoyo: con él, el salvaje y el idiota desaparecen detrás de su condición humana; y por su humanidad se convierte en motivo de tratamiento moral - hoy diríamos psicoterapeutico - continuado durante largo tiempo. (Postel; Quetel, 1987, p. 510)

0 marco empreendido por ltard é então de conjugar medicina e pedagogia, dando lugar à constituição de um saber médico sobre a criança considerada idiota, saber esse que se nomeará pouco depois como psiquiatria da criança ou psiquiatria infantil e que, além disso, influenciará a formação da Educação Especial. Vale dizer que o domínio do saber sobre a criança passa cada vez mais do universo pedagógico ao universo médico-psicológico.

As escalas de inteligência desenvolvidas por Binet e Simon contribuem para a instalação definitiva da psiquiatria infantil como ramo separado da psiquiatria geral. Os conceitos educável ou ineducável aplicáveis às crianças, frutos dos testes de inteligência e das determinações dos graus de deficiência mental considerados naquele momento, reafirmam a forte

2. Bercherie, P. A clínica psiquiátrica da criança: estudo histórico. Tradução Oscar Cirino. Artigo publicado originalmente em Ornicar? n. 26-27. Paris: Navarin, 1983. Em português, a primeira versão nos Fascículos Fhemig, n. 7. BH: Fhemig, 1992. A atual versão está em Cirino, 2001. 
ligação das propostas de tratamento da criança aos procedimentos pedagógicos, ou melhor: diagnóstico e tratamento das crianças são estabelecidos a partir das condições destas para o aprendizado, o que é fruto da difícil separação do sofrimento psíquico da criança de seu desenvolvimento psicológico e da expressão deste na apreensão pela criança dos códigos de moralidade vigentes, bem como de suas aquisições cognitivas. Vale dizer que esse tipo de diferenciação continua sendo objeto de discussão atual.

Apesar da constituição da psiquiatria infantil como ramo independente, conceitos da psiquiatria dos adultos começaram a ser utilizados para definir outras patologias que passaram a ser descritas na criança como, por exemplo, a demência precoce de Kraepelin e a demência precocíssima, definida por Sancte de Sanctis, que constituíram quadros de referência para pensar a loucura nas crianças (Postel; Quetel, 1987).

Bercherie, no entanto, ressalta que a partir da década de 1930 a psicanálise influencia fortemente o campo de investigação clínica da criança e essa influência se mantém presente até os anos 1980. De fato, isso contribuiu em muito para a diferenciação do campo de intervenções terapêuticas sobre a criança, separadas da clínica dos adultos. Entretanto, esta não parece ser mais a realidade da clínica com crianças.

Ao longo dos séculos XIX e XX, diversas instituições médico-pedagógicas para crianças surgiram na Europa bem como nos Estados Unidos. De suas histórias, recolhem-se tentativas de tratamento, mas os empreendimentos médico-pedagógicos fracassaram em restituir às crianças sua condição de aprendizado e pertencimento social.

Os desenvolvimentos da psiquiatria da criança são marcados, como na psiquiatria dos adultos, pela institucionalização e segregação. 0 movimento antipsiquiátrico cumpriu importante papel ao questionar a institucionalização da loucura, o poder do discurso médico sobre a doença e o sujeito, denunciando o fracasso dos tratamentos. No entanto, os efeitos de exclusão e as propostas terapêuticas disciplinadoras mantêm-se ainda vigentes, especialmente no caso das crianças. A medicalização e os diagnósticos descritivos são agora amplamente utilizados com as crianças. A diferença entre adultos e crianças aparece nublada com a aplicação do paradigma da psiquiatria biológica. No campo do orgânico, as diferenças entre adultos e crianças praticamente inexistem, já que neste a dimensão histórica está ausente.

Do ponto de vista do tratamento e da escolarização das crianças, as críticas de Maud Mannoni são ponto de partida fundamental. Suas críticas à pedagogia e seus efeitos excludentes, bem como ao poder técnico sobre o tratamento das crianças, institucionalizados nos centro médico-pedagógicos franceses, têm ainda hoje efeito sobre a lógica contemporânea das intervenções destinadas às crianças, sejam elas educativas ou terapêuticas.

Em vez de revolucionar o ensino e sua estrutura, o Ocidente prefere, pelo contrário, remediar os efeitos das anomalias geradas por um ensino inadequado à nossa época. Remediar os efeitos significa, neste caso, encarregar a medicina de responder onde o ensino fracassou. (Mannoni, 1988, p. 62)

Em termos terapêuticos, as terapias cognitivas, de tradição behaviorista, são as únicas atualmente aceitas como válidas pelo saber médico. Assim, vemos as crianças e suas famílias submetidas ao poder exercido pela constituição de um domínio de saber médico-psicológico sem que o contexto de seus sofrimentos, bem como sua possibilidade de tratamento, sejam orientados para outras formas de consideração da subjetividade que não a normalizante e de 'treinamento'.

Que o campo educativo esteja invadido pelos discursos técnicos, não é novidade. A cientificização dos discursos sobre a criança desde o início do século XX contribuiu não somente para a construção de um discurso pedagógico normalizador, mas também para a validação de um 
saber sobre a criança no campo das especialidades: psicologia, fonoaudiologia, psicopedagogia, psiquiatria etc. Os encaminhamentos para especialistas feitos pelas equipes escolares e a psicologização do ensino têm sido bastante discutidos por diversos autores.

Os trabalhos de Maria Helena Souza Patto, além disso, discutiram amplamente a produção do fracasso escolar, como fruto dos efeitos de discriminação das classes trabalhadoras, justificada pelo discurso científico psicologizante:

Como regra, o exame psicológico conclui pela presença de deficiências ou distúrbios mentais [leia-se hoje transtornos mentais] nos alunos encaminhados, prática que terá resultados diferentes de acordo com a classe social a que pertencem: em se tratando de crianças da média e da alta burguesia, os procedimentos diagnósticos levarão a psicoterapias, terapias pedagógicas e orientações de pais que visam a adaptá-las a uma escola que realiza os seus interesses de classe; no caso de crianças das classes subalternas, ela termina com um laudo que mais cedo ou mais tarde, justificará sua exclusão da escola. Nesse caso, a desigualdade e a exclusão são justificadas cientificamente (ou seja, com pretensa isenção e objetividade) através de explicações que ignoram a sua dimensão política e se esgotam no plano das diferenças individuais de capacidade. (Patto apud Patto, 2000 p. 65)

Algumas mudanças significativas na Educação têm ocorrido depois do início da defesa da Educação Inclusiva, algo que deve ser anotado, mas que não será discutido aqui. No entanto, também a partir daí, a escola tem convivido muito mais de perto com o discurso psiquiátrico, já que tem recebido crianças que estavam excluídas da escola antes mesmo de nela ingressarem, por terem sido consideradas, a partir de seus diagnósticos, ineducáveis ${ }^{3}$.

Com a hegemonia do discurso psiquiátrico sobre os sofrimentos e as disfunções comportamentais e cognitivas das crianças, vemos que a Educação encontra-se mais uma vez, ou mais intensamente, atravessada pelo discurso especialista.

Seria preciso resgatar e exercer algo do domínio do ato educativo nas escolas sem que este tivesse antes que estar vinculado à observação de especialistas ou à orientação destes, permitindo que as crianças tivessem ao menos um pertencimento social não atravessado por suas denominações ou rotulações diagnósticas. Esta talvez seja uma das grandes possibilidades que a Educação Inclusiva permite às crianças que estiveram até então fora da escola: estar na escola resgata um lugar social não conferido até pouco tempo atrás às crianças em grave sofrimento psíquico.

Se, por um lado, os profissionais da Educação se vêem destituídos de sua possibilidade de ação junto às crianças pela hegemonia do discurso das especialidades; por outro, ao assumir e validar os discursos médico-psicológicos, a pedagogia não deixa de fazer a manutenção dessa mesma prática, desresponsabilizando a escola e culpabilizando as crianças e suas famílias por seus fracassos.

0 discurso médico difundido na mídia leiga, em forma de artigos simplistas que naturalizam o sofrimento da criança e seus 'problemas de aprendizado', apresenta-se atualmente na escola de forma marcante. É comum que professores e coordenadores professem diagnósticos diante da observação de certos comportamentos das crianças, especialmente de Transtorno de Déficit de Atenção e Hiperatividade (TDAH), e as encaminhem para avaliação psiquiátrica, neurológica e/ou psicológica. É comum também que agentes das equipes escolares insistam em perguntar aos pais, quando se encontram diante de alguma manifestação não conhecida (ou não desejada) de uma criança que está em tratamento,

3. Persiste no discurso de muitos psiquiatras infantis no país a avaliação de que as crianças com deficiência mental e com diversos diagnósticos de psicose não devem, de forma alguma, frequentar a escola regular, sendo que suas matriculas, defendem, deveriam ser feitas em escolas especiais ou nas extintas (ou pelo menos deveriam ter sido) classes especiais. 
se ela foi corretamente medicada naquele dia. Tais procedimentos nos permitem entrever que estão crentes de que a variação no uso do remédio é responsável pela variação dos comportamentos e estados psíquicos da crianças, e que esta não teria nenhuma relação com variações, mudanças ou experiências no interior do cotidiano escolar.

Vemos que o fenômeno da psicologização da escola cede lugar a psiquiatrização do discurso escolar.

\section{Sofrimento psíquico recodificado: estratégia do biopoder}

0 discurso contemporâneo da psiquiatria biológica ou neuropsiquiatria descreve essencialmente os fenômenos humanos em termos de um funcionamento orgânico manipulável: retradução da fundação da clínica médica que buscava na anatomia o lócus dos fenômenos propriamente humanos.

A psiquiatria biológica, na medida em que se utiliza também dos estudos estatísticos e epidemiológicos, cumpre papel disciplinar sobre a população. 0 programa diagnóstico dos manuais constitui uma operação de classificação e distribuição dos sintomas em quadros regulares de transtornos e é a aplicação do conjunto sobre o relato pontual do indivíduo que determina sua nomeação e seu tratamento. Não é incomum observar, nas unidades de saúde ou mesmo nas escolas, que o nome do paciente ou do aluno seja substituído por sua classificação diagnóstica - estranha nomeação dos indivíduos que põe em relevo o lugar que ocupam na escala normal.

Da era clássica à pós-modernidade, vemos como, tomando os estudos de Foucault, a alma tornou-se pouco a pouco objeto de controle e disciplina apoderada pelos diversos discursos (religioso, militar, pedagógico, psiquiátrico, psicológico etc). No campo do discurso médico, os elementos mínimos do orgânico - os neurotransmissores e as funções da bioquímica cerebral - são os objetos a partir dos quais a medicina estabelece seu saber e seu poder sobre os sujeitos na contemporaneidade. Antes disso, Foucault (1987), em Vigiar e punir, já demonstrava como o poder da Norma operava, a partir dos exames diagnósticos, a produção de um saber sobre os indivíduos e sua sujeição aos domínios da ciência/das psicociências. 0 desenvolvimento do saber psiquiátrico esteve, de maneira geral, constantemente filiado às aplicações dessa técnica - o exame.

Todas as ciências, análises ou práticas com radical 'psico', têm seu lugar nessa troca histórica dos processos de individualização. 0 momento em que passamos de mecanismos histórico-rituais de formação da individualidade do homem memorável pela do homem calculável, esse momento em que as ciências do homem se tornaram possiveis, é aquele em que foram postas em funcionamento uma nova tecnologia do poder e uma nova anatomia política do corpo. (p. 161)

A ampla gama de sintomas presentes nos manuais bem como a forma diagnóstica proposta por eles permitem que muitos acontecimentos cotidianos, sofrimentos passageiros ou outros comportamentos, possam ser registrados como sintomas próprios de transtornos mentais. A socialização do DSM-IV na formação médica geral permite que clínicos de outras especialidades, que não a psiquiátrica, possam medicar com facilidade seus pacientes. Não se trata de sugerir a manutenção do domínio psiquiátrico nesse caso, mas de revelar a banalização do diagnóstico e o uso irrestrito de medicações como intervenção diante da vida. Alguns psiquiatras têm demonstrado sua preocupação em relação a esses efeitos:

Há uma psiquiatrização ocorrendo na sociedade. Já existem 500 tipos descritos de transtorno mental e do comportamento. Com tantas descrições, quase ninguém escaparia a um diagnóstico de problemas mentais. [...] Se a criança está agitada na escola, podem achar 
que está tendo um transtorno de atenção e hiperatividade. Coisas normais da vida estão sendo encaradas como patologias. [...] Houve um excesso de diagnósticos psiquiátricos. Essa variedade atende mais aos interesses e à saúde financeira da indústria que à saúde dos pacientes. (Costa e Silva apud Aguiar, 2004, p. 85)

Estamos atualmente, então, convivendo com sofrimentos codificados em termos de uma nomeação própria do discurso médico, que se socializa amplamente e passa a ordenar a relação do indivíduo com sua subjetividade e seus sofrimentos. Diante disso, as dimensões conflitiva, imprevisível, irredutível e inapreensível da subjetividade vêm sendo negadas e tratadas como meras abstrações psicanalítico-filosóficas.

Em História da sexualidade, Foucault (1977) analisa a passagem do poder soberano sobre a morte ao poder político de "gerir a vida', da era clássica à modernidade. Enfatiza a presença de dois mecanismos: o desenvolvimento das disciplinas do corpo no século XVIl e as regulações da população no século XVIIl. A articulação desses dois mecanismos de poder ao longo do século XIX, nas regulações da vida, configurará uma nova forma de poder definida por ele como biopoder.

As formas de viver, o exercício das possibilidades da vida, o cultivo da saúde, os domínios sobre a sexualidade, assim como os sofrimentos existenciais serão objeto de saber e poder.

A normalização da vida expressa no campo médico pela possibilidade de classificação dos indivíduos em termos diagnósticos, baseados também em estudos populacionais epidemiológicos, que definem atualmente algumas das políticas em saúde mental (tanto nas propostas de tratamento como em seu aspecto preventivo), pode ser inserida naquilo que Foucault nomeia como microfísica do poder sobre os corpos.

A produção de saber sobre o sofrimento psíquico encontra-se associada à produção da indústria farmacêutica de remédios que prometem aliviar os sofrimentos existenciais. 0 consumo em larga escala dos medicamentos e o crescimento exponencial da indústria farmacêutica tornam-se elementos indissociáveis do exercício do poder médico apoiado em um saber consolidado ao longo do século XX.

Alheios à estrutura social e à sua historicidade, o biologismo e o psicologismo mantêm-se à custa de uma análise a-histórica, quando não anti-histórica, das relações sociais antagônicas nas sociedades industriais capitalistas, análise na qual se enfatizam os elementos integrativos e normativos da vida social. (Patto apud Patto, 2000, p. 172)

Não se trata de rejeitar todo e qualquer uso dos psicofármacos, pois são inegáveis alguns de seus efeitos positivos tanto na vida de alguns como na possibilidade de transformação do sistema de cuidados e tratamento da loucura no século XX, mas de evidenciar os efeitos de um discurso que banaliza a existência, naturaliza os sofrimentos e culpabiliza os indivíduos por seus problemas e pelo cuidado de si (racionalização própria da economia neoliberal).

Trata-se também de encontrar na Educação uma possibilidade de não sujeição ao discurso psiquiátrico, libertando as crianças dos destinos previstos nos prognósticos médicos.

A permeabilidade do discurso pedagógico à cientificidade médico-psicológica parece também cumprir a função de dar consistência a certa metodologia capaz de dar conta daquilo que passou a ser considerado ponto fundamental no desenvolvimento cognitivo das crianças: as chamadas competências. Por outro lado, esse recurso permite um discurso que, baseado na noção de déficit, explicaria os fracassos experimentados no interior das escolas, estando estes ora do lado da criança, que não seria capaz de desenvolver as famosas competências em função de falhas presentes em seu organismo, ora do lado da metodologia pedagógica, não realizada ou construída de forma a estar adequada às mesmas competências das crianças.

Em um ou outro caso, o que se parece tentar evitar diz respeito àquilo que é inerente 
ao próprio ato educativo e à constituição dos sujeitos: sua imprevisibilidade e o fato de que ambos se dão no encontro com a alteridade. Evitar a imprevisibilidade e o outro, esse estranho outro, acaba por, de certa forma, desfazer a implicação do ato educativo como um ato constitutivo do sujeito.

Si educar es operar sobre el outro com el propósito de hacer del outro um semejante, em realidad se podría decir que nadie está preparado. [...]

En toda relación humana existe uma mutua intervención. Este es um debate interesante. No hay educación sin intervención. Enseñar ya es intervenir, hay que introducirse en un espacio que le pertenece al otro; existe una especie de violencia dada por la ocupación del territorio que es del otro. [...] Pero si creo de entrada que el otro no va a poder, si esta-belezco un juicio a priori de lo que va o no va a poder o si le dejo a la psicología decir qué es lo que puede y lo que no, entonces la escuela está condenada a desaparecer. La chance de sobrevivir no radica en las buenas intenciones sino en el ejercicio perseverante de la libertad que, si he sido claro, consiste en términos educativos en ofertar (enseñar) más alla o a pesar de todo cálculo, contexto, realidad, demanda o entrevista. (Trechos de entrevista com Estalislao Antelo, 2004)

0 recurso à técnica, seja ela a dos manuais de psicologia seja a do discurso médico hegemônico, tem tido efeitos não pouco nefastos sobre o discurso pedagógico nos tempos contemporâneos. A medicalização em larga escala das crianças nos tempos atuais pode ser lida também como apelo ao silêncio dos conflitos, negando-os como inerentes à subjetividade e ao encontro humano. Que o discurso pedagógico contribua para a manutenção desse tipo de recurso deve ser objeto constante de crítica em direção à possibilidade de que o lugar do ato educativo seja redefinido.

\section{Referências bibliográficas}

AGUIAR, A. A. A psiquiatria no divã: entre as ciências da vida e a medicalização da existência. Rio de Janeiro: Relume Dumará, 2004.

ANTELO, E. Que quiere usted de mi? Lo incalculable en el oficio de enseñar. Revista La Educación en Nuestras Manos. n. 72 , Octubre de 2004. (versão on-line)

BERCHERIE, P. A clínica psiquiátrica da criança: estudo histórico. In: CIRINO, 0. Psicanálise e psiquiatria com crianças: desenvolvimento ou estrutura. Belo Horizonte: Autêntica, 2001. p. 127-144.

BIRMAN, J. Mal-estar na atualidade: a psicanálise e as novas formas de subjetivação. Rio de Janeiro: Civilização Brasileira, 1999. p. $175-193$.

BOLGUESE, M. S. Depressão \& Doença nervosa moderna. São Paulo: Via Lettera; Fapesp, 2004.

FOUCAULT, M. História da sexualidade I: a vontade de saber. Rio de Janeiro: Graal, 1977.

Vigiar e punir: nascimento da prisão. Petrópolis: Vozes, 1987. Terceira Parte, capítulos I e II.

KUPFER, M. C. M. Educação para o futuro: psicanálise e educação. São Paulo: Escuta, 2001.

MANNONI, M. Educação impossível. Rio de Janeiro: Francisco Alves, 1988. 
PATTO, M. H. S. Para uma crítica da razão psicométrica. In: Mutações do cativeiro: escritos de psicologia e política. São Paulo: Edusp, 2000, p. 65-83.

Mutações do cativeiro: caminhos da semiformação. In: Mutações do cativeiro: escritos de psicologia e política. São Paulo: Edusp, 2000, p. 157-185.

POSTEL, J.; QUÉTEL, C. Historia de la psiquiatria. Cidade do México: Biblioteca de Psicologia y Psicoanalisis,1987. Caps. XXV, $X X V I$ e XXVII.

ROUDINESCO, E. Por que a psicanálise? Rio de Janeiro: Jorge Zahar, 2000.

SILVA Jr., N. Sobre a re-codificação mercantil do sofrimento. In: BOLGUESE, M. S. Depressão \& Doença nervosa moderna. São Paulo: Via Lettera; Fapesp, 2004. p. 9-14.

Recebido em 26.09.05

Aprovado em 17.04.06

Renata Guarido é graduada pelo IPUSP em 1993, atuou como psicóloga na Creche Central da USP durante sete anos, atualmente faz parte da Equipe Clínica da Pré-Escola Terapêutica Lugar de Vida - IPUSP -, que atende, para tratamento e acompanhamento da escolarização, crianças em graves sofrimentos psíquicos. Psicóloga, mestranda em Psicologia da Educação pela Faculdade de Educação da Universidade de São Paulo. 